\begin{tabular}{|l|l|l||}
\hline \multicolumn{2}{|c|}{ PublisherInfo } \\
\hline \hline PublisherName & $:$ & BioMed Central \\
\hline \hline PublisherLocation & $:$ & London \\
\hline \hline PublisherImprintName & $:$ & BioMed Central \\
\hline \hline
\end{tabular}

\title{
Apoptosis and caspases in breast cancer
}

\begin{tabular}{|l|l|l||}
\hline \multicolumn{2}{|c||}{ ArticleInfo } \\
\hline \hline ArticleID & $:$ & 3642 \\
\hline \hline ArticleDOI & $:$ & $10.1186 /$ bcr-1999-66620 \\
\hline \hline ArticleCitationID & $:$ & 66620 \\
\hline \hline ArticleSequenceNumber & $:$ & 62 \\
\hline \hline ArticleCategory & $:$ & Paper Report \\
\hline \hline ArticleFirstPage & $:$ & 1 \\
\hline \hline ArticleLastPage & $:$ & 3 \\
\hline \hline & & RegistrationDate : 1999-11-1 \\
\hline ArticleHistory & $:$ & OnlineDate \\
\hline ArticleCopyright & $:$ & Current Science Ltd1999-11-1 \\
\hline \hline ArticleGrants & $:$ & \\
\hline \hline ArticleContext & $:$ & 1305811 \\
\hline \hline
\end{tabular}




\section{Keywords}

Apoptosis, breast, carcinoma, caspase

\section{Introduction}

Caspases are involved in the terminal stages of apoptosis. At least 13 mammalian caspases have been identified, which act in a cascade manner, eventually leading to the demise of a cell by apoptosis. In malignant tumours, including breast, there is evidence that increased apoptotic index is associated with higher tumour grade.

\section{Aims}

To examine the expression of caspases 3,6 and 8 and their association with apoptosis in preneoplastic and neoplastic breast lesions.

\section{Comments}

A clear relationship has been demonstrated between the rate of apoptosis and the expression of three key caspases involved in the apoptotic cascade. However, the immunohistochemistry techniques used cannot differentiate between active and inactive forms of caspases, which could be the focus of future work. The expression and activities of anti-apoptotic factors such as $b c l-2$ should also be considered.

\section{Methods}

Paraffin embedded sections from 180 breast lesions (82 invasive carcinomas, 74 in situ carcinomas, 15 atypical hyperplasias and 9 benign epithelial hyperplasias) were used. An apoptotic index was determined for each sample using the TUNEL method which was validated using morphological criteria. 
The expression of caspases 3, 6 and 8 was assessed by immunohistochemistry using specific antibodies. A scoring system was used to evaluate both qualitative and quantitative immunostaining.

\section{Results}

Compared with normal breast epithelium, increased caspase 3 immunopositivity was observed in $22 \%$ of benign epithelial hyperplasias, $25 \%$ of atypical hyperplasias, $58 \%$ of in situ carcinomas and $90 \%$ of invasive carcinomas. Staining was mainly diffuse and intracytoplasmic. The corresponding percentage expression for caspase 6 and 8 was $11 \%, 25 \%, 60 \%, 87 \%$ and 22\%, 57\%, 84\%, 83\%, respectively. As well as showing diffuse intracytoplasmic staining, caspase 6 and 8 also showed a granular staining pattern, the extent of which varied between tumours. With in situ lesions, immunoreactivty of all three caspases increased according to histological progression. The apoptotic index was reduced in benign and atypical hyperplasias compared to in situ or invasive carcinomas, but was not related to oestrogen or progesterone receptor expression. Overall, strong caspase 3, 6 and 8 immunopositivity was significantly associated with the extent of apoptosis.

\section{Discussion}

This paper has shown that as breast tumours progress, there is a gradual rise in the expression of caspases 3, 6 and 8. Further more, expression of these caspases is strongly associated with an increase in apoptosis, with a direct relationship between the apoptotic index and the histological aggressiveness of a breast lesion. Expression of genes such as $p 53$ and $c-e r b-B 2$ are also increased in higher grade tumours. It is possible that such genes may be responsible for the increased apoptotic rate observed in these tumours.

\section{References}

1. Vakkala M, Paakko P, Soini Y: Expression of caspases 3,6 and 8 is increased in parallel with apoptosis and histological aggressiveness of the breast lesion. Br J Cancer. 1999, 81: 592-599. 